\section{Heterocontrole da fluoretação das águas em três cidades no Piauí, Brasil}

\author{
Monitoring water fluoridation in three cities in \\ Piauí State, Brazil
}

\author{
1 Programa de Pós-graduação \\ em Odontologia, \\ Universidade Federal da \\ Paraíba, João Pessoa, Brasil. \\ 2 Universidade Federal do \\ Piauí, Teresina, Brasil. \\ 3 Universidade Estadual do \\ Piauí, Floriano, Brasil. \\ Correspondência \\ F. C. Sampaio \\ Programa de Pós-graduação \\ em Odontologia, \\ Universidade Federal da \\ Paraíba. \\ Rua Mario Batista Junior 75, \\ apto. 602, João Pessoa, PB \\ 58043-130, Brasil. \\ fabio.sampa@uol.com.br
}

\section{Abstract}

This study aimed to monitor the fluoride concentration in the public water supply in Teresina, Floriano, and Parnaíba, Piauí State, Brazil. Samples were collected monthly for one year between 2004 and 2005. Six sites in each city were randomly selected for water sampling (total $n=$ 576), 192 in each city. Fluoride assays were performed in duplicate, using a specific electrode. Most samples were below the optimum fluoride concentration, and only $4.3 \%(n=25)$ presented acceptable values (0.60-0.80ppm). Acceptable samples totaled $7.8 \%(n=15), 4.7 \%(n=9)$, and 0.5\% ( $n=1)$ in Teresina, Floriano, and Parnaíba, respectively. By conclusion, fluoride levels in the public water supply in the three cities were below the optimum concentration, and a permanent surveillance system is thus needed to guarantee effective water fluoridation in the State of Piauí.

Fluorine; Fluoridation; Water Supply; Surveillance
Josiene Saibrosa da Silva 1

Cinthya Melo do Val 2

Juliana Nolêto Costa 3

Marcoeli Silva de Moura 2

Thais Alves Elias Silva 2

Fábio Correia Sampaio 1

\section{Introdução}

A cárie dentária é uma doença complexa resultante da interação de muitos fatores de risco 1 . A prevalência dessa doença tem diminuído em muitos países do mundo a partir de medidas preventivas. As principais ações, comprovadamente, eficazes são: correta higiene bucal, controle da dieta e a utilização de fluoretos. Entretanto, como a possibilidade de sucesso das duas primeiras medidas em saúde pública está relacionada a problemas culturais e comportamentais complexos, o declínio dos índices de cárie tem sido associado, primordialmente, à ação dos fluoretos 2 .

A fluoretação da água de consumo público tem sido considerada a medida de saúde pública mais próxima do ideal no controle da cárie dentária porque os benefícios podem transcender todas as raças, etnias e diferenças sócio-econômicas e religiosas 3 . Por esse motivo, a fluoretação de águas é considerada um dos mais importantes fatores responsáveis pelo declínio da cárie dentária durante a segunda metade do século XX 4 , inclusive apresentando a melhor relação custobenefício de todos os métodos preventivos 5,6. No Brasil, a adição de flúor na água encanada custa aproximadamente $\mathrm{R} \$ 1,00$ (Hum Real) por habitante ao ano (Programa Brasil Sorridente. Informativo 2004; fev/mar), aspecto que concorre para que os custos com serviços dentários sejam consideravelmente reduzidos após a implantação desta medida 7 . Todavia, para que haja uma 
redução da cárie dentária é necessário que a fluoretação seja contínua e sem interrupções ${ }^{3}$. A permanência dos níveis de flúor é necessária devido à ação deste íon nos processos de desmineralização e remineralização que ocorrem constantemente na cavidade bucal, já que o efeito da atividade anticariogênica da água fluoretada resulta principalmente da ação tópica do flúor 8,9.

O heterocontrole é a vigilância sanitária das concentrações de flúor realizado por qualquer órgão ou instituição, pública ou privada, que não seja a empresa responsável pelo tratamento e adição do flúor na água 10 . Nesse sentido, o heterocontrole tem sido motivado para garantir a eficácia da fluoretação das águas no controle da cárie dentária, bem como para prevenir episódios de fluorose dentária 11,12,13.

No Brasil, uma das razões que justificam plenamente a adoção da fluoretação das águas é que, além de ser economicamente justificável, a medida beneficia mais aos que mais necessitam dela, pois seu impacto preventivo é maior exatamente nos segmentos populacionais de piores condições sócio-econômicas. Assim sendo, não fluoretar a água no Brasil ou interromper sua continuidade deve ser considerado uma atitude juridicamente ilegal (Lei no. 6.050/74), cientificamente insustentável e socialmente injusta 14

Em 2004, o governo federal afirmou que 40 milhões de brasileiros eram beneficiados com a fluoretação das águas (Programa Brasil Sorridente. Informativo 2004; fev/mar) e as diretrizes de saúde bucal do Brasil apontavam para a fluoretação das águas de abastecimento como prioridade governamental, por meio do Programa Brasil Sorridente - subcomponente fluoretação das águas 15.

No Piauí, a fluoretação de águas existe desde o final da década de 70 e pouco tem sido estudado desde a implantação deste método 16. A água da cidade de Teresina teve sua fluoretação iniciada no ano de 1978, utilizando-se fluorsilicato de sódio. Em 1986, a fluoretação foi interrompida, sendo reiniciada em 1997 com a utilização do ácido fluorsilícico ${ }^{16}$. Com relação à fluoretação em Parnaíba e Floriano, não existem documentos públicos disponíveis sobre a implantação desta medida nestes municípios, e nem registros científicos sobre este tema. Tendo em vista que a fluoretação dos sistemas de abastecimento é uma grande medida de saúde pública, e da importância do heterocontrole para esta medida, objetiva-se monitorar as concentrações de flúor na água de abastecimento público de Teresina, Floriano e Parnaíba, cidades do Piauí com sistema de fluoretação de águas no Estado.

\section{Material e método}

\section{Caracterização do estudo}

O presente estudo caracteriza-se como sendo do tipo observacional e longitudinal, visto que a coleta das amostras foi mensal por um período de um ano.

\section{Área do estudo}

Os municípios do estudo são: Teresina, Floriano e Parnaíba, todos localizados no Estado do Piauí, Brasil. Cada sede municipal está dividida administrativamente em cinco regiões. A principal fonte de abastecimento para esses três municípios é caracterizada como manancial de superfície (Rio Parnaíba). Todos são contemplados com sistema de fluoretação das águas e têm média de temperatura anual em torno de $28^{\circ} \mathrm{C} 18$, o que requer uma concentração ótima de flúor de $0,7 \mathrm{ppm}$, com valores aceitáveis entre 0,6 e $0,8 p p m ~ 18$. O controle operacional do flúor na água é realizado pela Empresa de Tratamento de Águas e Esgotos do Piauí (AGESPISA) por meio do método colorimétrico de alizarina (AGESPISA. Declaração de 24 de outubro de 2005).

\section{Amostras}

Para seleção dos pontos de coleta das amostras, inicialmente sorteou-se um bairro representativo de cada uma das regiões administrativas que compõem cada município. Em seguida, selecionou-se aleatoriamente uma unidade de saúde pública estabelecida no bairro sorteado anteriormente. Depois, foi escolhida em cada unidade de saúde uma torneira abastecida por água proveniente da Estação de Tratamento de Água (ETA) do município. Foi selecionada também uma amostra proveniente diretamente da ETA ou de uma torneira próxima abastecida pela mesma ETA, totalizando seis pontos de coleta de amostras em cada um dos três municípios.

\section{Coleta das amostras}

As coletas foram realizadas mensalmente, durante 12 meses, segundo metodologia de Schneider Filho et al. 10, em tubos Eppendorf de 2mL, em número de três amostras por ponto e uma amostra por ETA, totalizando 16 amostras por mês em cada município. Optou-se por realizar as coletas em dias aleatórios da semana e do mês. Após a coleta, as amostras foram acondicionadas em caixas de isopor e enviadas imediatamente via Empresa Brasileira de Correios e Telégrafos 
à Universidade Federal da Paraíba (UFPB) para análise laboratorial.

\section{Análise das amostras}

Todas as amostras foram analisadas até oito dias após a coleta. A análise da concentração de flúor foi realizada no Laboratório de Biologia Bucal da UFPB, utilizando-se um eletrodo específico (Orion modelo 9609; Orion Research Inc., Estados Unidos) e um analisador de íons (Orion modelo 710-A; Orion Research Inc., Estados Unidos). As amostras foram analisadas em duplicata com tampão TISAB II na proporção de 1:1, utilizando-se volume de $0,5 \mathrm{~mL}$ de cada. A calibração do equipamento foi realizada em triplicata, utilizando-se soluções de padrão de flúor em concentrações de 0,125 a 1,3ppm F. As soluções padrão eram obtidas de diluição seriada a partir de uma solução padrão de 100ppm F (Orion). A calibração foi checada a cada hora com soluções padrão de flúor com concentração conhecida. As leituras em $\mathrm{mV}$ foram transformadas em concentração (teor) de flúor (ppm F) no programa Microsoft Excel. Foram aceitas apenas curvas de calibração com variação menor ou igual a 5\%.

\section{Análise dos dados}

A concentração de flúor foi calculada pela média das leituras das amostras analisadas para cada ponto de coleta. O total de amostras com concentração dentro da faixa aceitável $(0,60$ a 0,80ppm F) foi contabilizado para cada município. Os dados foram tabulados para cada município por meio de freqüências simples.

\section{Resultados}

Verifica-se na Tabela 1 que do total das amostras analisadas em Teresina apenas $7,8 \%(n=15)$ estavam dentro da faixa aceitável de concentração de flúor (0,60 a 0,80ppm). Em Floriano e Parnaíba esses valores foram de apenas $4,7 \%(n=9)$ e $0,5 \%$ $(n=1)$, respectivamente. No total, das 576 amostras analisadas neste estudo, apenas 4,3\% ( $\mathrm{n}=$ 25) apresentaram valores aceitáveis de flúor para o controle da cárie dentária. Ressalta-se que não houve perda de nenhuma amostra nas etapas de coleta e análise do presente trabalho.

Na Tabela 2 observa-se que pelos valores da média nenhum município pesquisado apresentou concentrações de flúor na faixa dos valores aceitáveis. A concentração média de flúor mais próxima do ideal foi observada em Teresina no mês de novembro. Nenhuma amostra com valor superior a $0,8 \mathrm{ppm}$ de flúor foi observada neste estudo. Não houve diferenças na concentração de flúor entre as áreas administrativas de cada cidade, exceto na zona leste de Teresina que eventualmente apresentou valores inferiores (>0,2ppm) em relação às outras áreas da cidade.

\section{Discussão}

A metodologia utilizada para coleta e análise das amostras seguiu protocolo-padrão para estudos desta natureza 10,19. Priorizou-se a determinação dos pontos de coleta baseada na divisão administrativa das três cidades em estudo (Teresina, Parnaíba e Floriano), tendo em vista que cada uma apresenta uma única ETA que abastece a zona urbana. Todavia, estabeleceu-se um maior número de pontos de coleta, no sentido de proporcionar mais informações que contribuíssem para os valores finais.

Na Tabela 1, constata-se que a maioria das amostras não atingiu a faixa aceitável $(0,60$ a

Tabela 1

Distribuição da freqüência absoluta e porcentual de amostras mensuradas e amostras na faixa aceitável, segundo municípios pesquisados. Piauí, Brasil, 2005.

\begin{tabular}{|c|c|c|c|c|}
\hline \multirow[t]{2}{*}{ Município } & \multicolumn{2}{|c|}{ Total de amostras coletadas } & \multicolumn{2}{|c|}{ Total de amostras na faixa aceitável * } \\
\hline & $\mathbf{n}$ & $\%$ & $\mathbf{n}$ & $\%$ \\
\hline Teresina & 192 & 100,0 & 15 & 7,8 \\
\hline Floriano & 192 & 100,0 & 9 & 4,7 \\
\hline Parnaíba & 192 & 100,0 & 1 & 0,5 \\
\hline Total & 576 & 100,0 & 25 & 4,3 \\
\hline
\end{tabular}

* 0,6 a $0,8 p p m$ F. 
Tabela 2

Média e desvio-padrão (DP) das concentrações de flúor nas águas de abastecimento das cidades de Teresina, Floriano e Parnaíba por 12 meses entre 2004 e 2005. Piauí, Brasil.

\begin{tabular}{|c|c|c|c|c|c|c|}
\hline \multirow[t]{2}{*}{ Mês/Ano } & \multicolumn{2}{|c|}{ Teresina } & \multicolumn{2}{|c|}{ Floriano } & \multicolumn{2}{|c|}{ Parnaíba } \\
\hline & Média & DP & Média & DP & Média & DP \\
\hline Agosto/2004 & 0,07 & 0,04 & 0,22 & 0,12 & 0,14 & 0,02 \\
\hline Setembro/2004 & 0,22 & 0,04 & 0,30 & 0,08 & 0,22 & 0,13 \\
\hline Outubro/2004 & 0,32 & 0,11 & 0,35 & 0,14 & 0,38 & 0,09 \\
\hline Novembro/2004 & 0,53 & 0,26 & 0,14 & 0,02 & 0,16 & 0,08 \\
\hline Dezembro/2004 & 0,49 & 0,24 & 0,23 & 0,10 & 0,25 & 0,15 \\
\hline Janeiro/2005 & 0,27 & 0,18 & 0,21 & 0,13 & 0,19 & 0,06 \\
\hline Fevereiro/2005 & 0,29 & 0,18 & 0,22 & 0,10 & 0,07 & 0,02 \\
\hline Março/2005 & 0,18 & 0,13 & 0,37 & 0,07 & 0,07 & 0,04 \\
\hline Abril/2005 & 0,21 & 0,13 & 0,41 & 0,23 & 0,22 & 0,04 \\
\hline Maio/2005 & 0,27 & 0,24 & 0,37 & 0,29 & 0,11 & 0,04 \\
\hline Junho/2005 & 0,03 & 0,01 & 0,19 & 0,05 & 0,16 & 0,08 \\
\hline Julho/2005 & 0,03 & 0,01 & 0,19 & 0,03 & 0,10 & 0,08 \\
\hline Total & 0,24 & 0,07 & 0,27 & 0,06 & 0,17 & 0,03 \\
\hline
\end{tabular}

* 0,6 a 0,8ppm F.

0,80ppm F). Esse fato é indicativo de que as populações de Teresina, Parnaíba e Floriano não estiveram efetivamente expostas aos benefícios do flúor pela água, no período de agosto de 2004 a julho de 2005.

Nesse âmbito, quando se considera o total de amostras analisadas no presente estudo $(n=576)$, constata-se que apenas $4,3 \%$ estavam dentro da faixa aceitável. Ou seja, 95,7\% das amostras possuíam concentrações inadequadas de flúor. O estudo de Maia et al. 20 apresenta resultado semelhante em Niterói, Rio de Janeiro. Falhas do controle da fluoretação tem sido verificada por estudos tanto no Nordeste como em outras regiões do país 21,22,23,24,25. A situação observada na cidade de São Paulo é diferente pois das amostras examinadas, $93 \%$ estavam com concentração de flúor em níveis considerados ótimos 12 .

Outro aspecto a ser considerado, em relação a esses municípios piauienses, é a indisponibilidade de relatórios de controle operacional pela AGESPISA. Acrescenta-se, também, a falta de um sistema de vigilância sanitária permanente nesses municípios. Ainda nesse contexto, ressaltase a necessidade de por norma legal, a empresa de saneamento encaminhar, mensalmente, um relatório das medidas diárias de controle operacional da fluoretação ao órgão incumbido da vigilância sanitária 12. Por meio dessas medidas seria possível melhorar a qualidade do controle da fluoretação das águas e fazer com que o Poder Público Municipal exerça efetivamente as com- petências que, nesta área, atribuem-lhe tanto o texto constitucional quanto a lei orgânica da saúde.

Para a AGESPISA as baixas concentrações, porventura, detectadas nas redes de distribuição ocorrem por fatores relacionados à temperatura, à instabilidade do produto (flúor) e aos casos de manutenção do sistema (AGESPISA. Declaração de 24 de outubro de 2005). Ressalta-se que essa empresa utiliza o método colorimétrico de alizarina, que é sujeito a erros de leitura devido à presença de íons interferentes na água 26 . Sabendo-se que apenas uma minoria das amostras analisadas $(n=25)$ estava dentro da faixa de concentração aceitável ( 0,60 a 0,80ppm F), faz-se necessário que o heterocontrole seja permanente e que a empresa utilize métodos mais confiáveis para o controle das concentrações de flúor.

Segundo o Atlas de Abastecimento da Água do Piauí 27 , apesar das dificuldades que a população encontra em seu cotidiano, em termos de limitações de atividades que lhe garantam uma sobrevivência em padrões dignos, pode-se afirmar que o cidadão piauiense é muito mais vítima de falhas na administração pública dos recursos hídricos do que da própria natureza que o abriga. Isso confirma que falhas na administração pública, no campo técnico e político, são responsáveis pelas baixas concentrações de flúor em Teresina, Parnaíba e Floriano, comprometendo a credibilidade da fluoretação no Piauí. Portanto, uma repercussão negativa sobre a fluoretação de águas 
pode dificultar a implantação de outros sistemas de fluoretação de águas apesar do suporte governamental para a fluoretação de águas (Programa Brasil Sorridente. Subcomponente fluoretação da água, versão preliminar II; dados não publicados)

O Piauí não apresenta legislação estadual sobre a fluoretação e segue a legislação nacional. O Brasil confirmou sua posição em relação à fluoretação no ano de 2003, quando rejeitou o Projeto de Lei no. 510 que propunha a revogação da Lei $n^{\circ}$. 6050/74. O governo federal elaborou um parecer, subscrito por dezenas de entidades das áreas de saúde e saneamento, que defendia a continuidade da fluoretação das águas no Brasil, reiterava sua segurança e reconhecia a medida como um direito básico de cidadania. Recentemente, surgiu um novo projeto de lei que propõe a proibição da fluoretação das águas de abastecimento no Brasil e a permissão da utilização de flúor somente através da aplicação tópica deste elemento na profilaxia da cárie dentária (Grupo de Estudos em Saúde Bucal Coletiva de Sergipe. Carta aberta contrária ao Projeto de Lei do Senado no. 297; 2005).

Verifica-se, ainda, que além de uma vontade política, a fluoretação das águas deva ser considerada como um direito de cidadania. Existem razões para admitir que, quando não há controle público (social), a fluoretação das águas pode ser interrompida sem que o fato seja percebido por seus efeitos imediatos 28 .

Diante do exposto, espera-se que a divulgação dos dados sobre a situação da fluoretação de águas no Piauí motive o controle social para esta medida no estado e ressalte a importância deste método preventivo de saúde bucal coletiva, garantindo sua continuidade no futuro. Acredita-se que o subcomponente fluoretação da água, do Programa Brasil Sorridente, seja um programa facilitador que oriente e estimule a implantação da fluoretação de águas no maior número possível de municípios piauienses, bem como ressalte a importância do heterocontrole nos municípios onde esta medida seja implementada.

\section{Conclusões}

A maioria das amostras de água das cidades com fluoretação de águas (Teresina, Parnaíba e Floriano) apresentou concentrações de flúor abaixo do nível aceitável para o controle da cárie dentária;

Existe a necessidade de programar medidas de controle e heterocontrole permanentes através das estratégias de vigilância sanitária, para garantir a eficácia da fluoretação de águas no Estado do Piauí.

\section{Resumo}

O objetivo deste trabalho foi monitorar as concentrações de flúor na água de abastecimento público de Teresina, Floriano e Parnaíba, municípios do Piauí, Brasil. A coleta das amostras foi mensal por um período de um ano entre 2004 e 2005. Selecionaram-se aleatoriamente seis pontos de coleta de amostras de água em cada um dos três municípios, totalizando 576 amostras, sendo 192 por cidade. As análises de flúor foram realizadas em duplicata, utilizando-se um eletrodo específico. Os resultados demonstraram que a maioria da amostras ficou abaixo da concentração de flúor ideal e apenas 4,3\% $(n=25)$ das amostras coletadas apresentaram valores aceitáveis de flúor (0,60 a 0,80ppm). Por cidade, o percentual de amostras aceitáveis foi de 7,8\% ( $n=15), 4,7 \%(n=9)$ e 0,5\% $(n=1)$ para Teresina, Floriano e Parnaíba, respectivamente. Conclui-se que as concentrações de flúor na água de abastecimento público das cidades avaliadas estão abaixo do ideal e que existe a necessidade de implantar medidas de controle e heterocontrole permanentes para garantir a eficácia da fluoretação de águas no Estado do Piauí.

Flúor; Fluoração; Abastecimento de Água; Vigilância

\section{Colaboradores}

J. S. Silva participou da análise laboratorial e redação do artigo. M. S. Moura e T. A. E. Silva participaram da coleta das amostras em Teresina. J. N. Costa participou da coleta das amostras em Floriano. C. M. Val participou da coleta das amostras em Parnaíba. F. C. Sampaio participou da redação e revisão do artigo.

\section{Agradecimentos}

Este trabalho é parte da Dissertação de Mestrado do primeiro autor (J.S.S.) apresentada ao Mestrado em Odontologia da UFPB, área de concentração em Odontologia Preventiva e Infantil. Agradecemos à Coordenação de Aperfeiçoamento de Pessoal de Nível Superior (CAPES) pelo suporte financeiro. 


\section{Referências}

1. Fejerskov O. Changing paradigms in concepts on dental caries: consequences for oral health care. Caries Res 2004; 38:182-91.

2. Murray J. Bases para prevenção de doenças bucais. São Paulo: Editora Santos; 1992.

3. Ripa LW. A half-century of community water fluoridation in the United States: review and commentary. J Public Health Dent 1993; 53:17-44.

4. Centers for Disease Control and Prevention. Achievements in public health, 1900-1999: fluoridation of drinking water to prevent dental caries. MMWR Morb Mortal Wkly Rep 1999; 48:933-40.

5. Garcia AL. Caries incidence and costs of preventive programs. J Public Health Dent 1989; 49:259-71.

6. Marthaler TM. Sucesses and drawbacky in the caries preventive use of fluorides - lessons to be learnt from history. Oral Health Prev Dent 2003; 1:129-40.

7. Basting RT, Pereira AC, Meneghim MC. Avaliação da prevalência de cárie dentária em escolares do Município de Piracicaba, SP, Brasil, após 25 anos de fluoretação das águas de abastecimento público. Rev Odontol Univ São Paulo 1997; 11:287-92.

8. Assis GF, Buzalaf MAR, Faria FAC, Granjeiro JM, Torres AS, Lara VS, et al. Mecanismos biológicos e influência de fatores ambientais na fluorose dentária e a participação do flúor na prevenção da cárie. Rev Fac Odontol Bauru 1999; 7:63-70.

9. Groeneveld A, van Eck AAMJ, Backer-Dirks O. Fluoride in caries prevention: is effect pre- or posteruptive? J Dent Res 1990; 69:723-7.

10. Schneider Filho DA, Prado IT, Narvai PC, Barbosa SE. Fluoretação da água. Como fazer a vigilância sanitária? Rio de Janeiro: Rede Cedros; 1992. (Série Cadernos de Saúde Bucal, 2).

11. Domingues JEG. A vigilância sanitária em fluoretação de águas de abastecimento público - uma análise de suas necessidades [Monografia de Especialização]. Natal: Universidade Federal do Rio Grande do Norte; 1995.

12. Narvai PC. Vigilância sanitária da fluoretação das águas de abastecimento público no Município de São Paulo, Brasil, no período de 1990-1999 [Tese de Livre Docência]. São Paulo: Faculdade de Saúde Pública, Universidade de São Paulo; 2001.

13. Pelletier AR. Maintenance of optimal fluoride levels in public water systems. J Public Health Dent 2004; 64:237-9.

14. Ministério da Saúde. Parecer sobre Projeto de Lei no. 510/03. Dispõe contra a revogação Lei no. 6050/74. http://dtr2001.saude.gov.br/sps/ areastecnicas/bucal/home.htm (acessado em 22/ $\mathrm{Jul} / 2003)$
15. Ministério da Saúde. Diretrizes da Política Nacional de Saúde Bucal. http://www.saude.gov.br/ (acessado em 26/Jul/2005).

16. Moura MS, Silva JS, Simplício AHM, Cury JA. Avaliação longitudinal da fluoretação da água de abastecimento público de Teresina-Piauí. Rev Odonto Ciênc 2005; 20:132-6.

17. Silva Neto FS, Santos VS. História e geografia do Piauí. 2a Ed. Teresina: Freire \& Comp. Ltda.; 1994.

18. Galagan DJ, Vermillion JR. Determining optimum fluoride concentrations. Public Health Rep 1957; 72:491-3.

19. Ramires I, Grec RHC, Cattan L, Moura PG, Lauris JRP, Buzalaf MAR. Evaluation of the fluoride concentration and consumption of mineral water. Rev Saúde Pública 2004; 38:1-7.

20. Maia LC, Valença AMG, Soares EL, Cury JA. Controle operacional da fluoretação da água de Niterói, Rio de Janeiro, Brasil. Cad Saúde Pública 2003; 19:61-7.

21. Alves NSS, Sampaio FC. Fluoretação de águas no Estado da Paraíba situação atual e perspectivas. Revista da Aboprev 2004; 7:40-6.

22. Barros ERC, Tovo MF, Scapini C. Análise crítica da fluoretação de águas. RGO 1990; 38:247-54.

23. Lima FG, Lund RG, Justino LM, Demarco FF Del Pino FAB, Ferreira R. Vinte e quatro meses de heterocontrole da fluoretação das águas de abastecimento público de Pelotas, Rio Grande do Sul, Brasil. Cad Saúde Pública 2004; 20:422-9.

24. Silva MFA, Melo E, Pinheiro C, Tavares P, Barros $\mathrm{M}$, Rocha L. Concentração de flúor na água das cidades alagoanas. In: Resumos do III Encontro de Pós-graduação e Pesquisa. João Pessoa: Universidade Federal da Paraíba; 2000.

25. Buzalaf MA, Granjeiro JM, Damante CA, Ornelas F. Fluctuations in public water fluoride level in Bauru, Brazil. J Public Health Dent 2002; 62:173-6.

26. Maier F. Fluoración del água potable. México DF: Editorial Limusa/Wiley; 1971.

27. Governo do Estado do Piauí. Atlas do abastecimento da água do Piauí. Abastecimento de sedes municipais com menos de 5.000 habitantes Resumo Executivo, 2005. http://www.pi.gov.br/ bancodados.php (acessado em 26/Jul/2005).

28. Narvai PC, Frazão P, Fernandez RAC. Fluoretação da água e democracia. Saneas 2004; 2:29-33.

Recebido em 10/Jan/2006

Versão final reapresentada em 10/Ago/2006

Aprovado em 12/Dez/2006 